
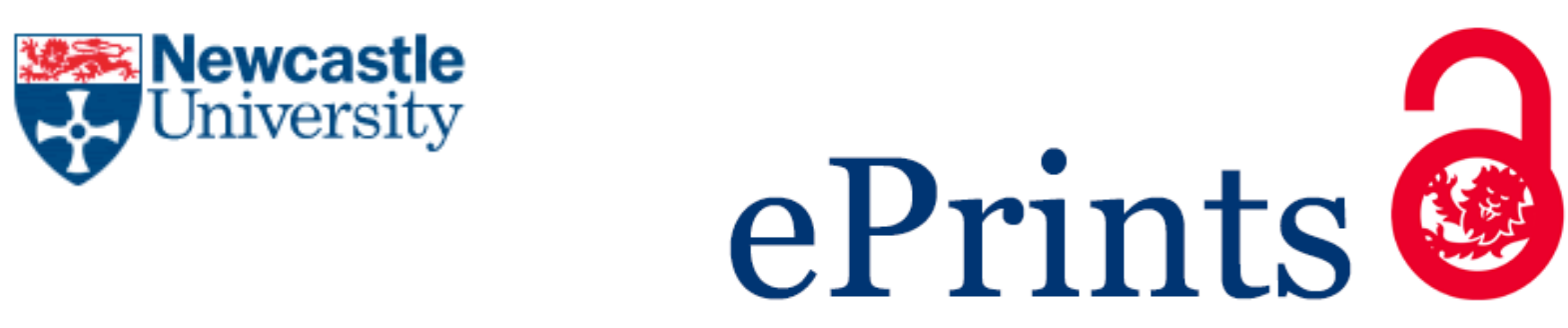

Raynor R.

(De)composing Habit in Theatre-as-Method.

Geohumanities, 2017

DOI: http://doi.org/10.1080/2373566X.2016.1258321

\title{
Copyright:
}

This is an Accepted Manuscript of an article published by Taylor \& Francis in Geohumanities on 23/01/2017, available online: http://www.tandfonline.com/10.1080/2373566X.2016.1258321.

DOI link to article:

http://doi.org/10.1080/2373566X.2016.1258321

Date deposited:

$15 / 03 / 2017$

Embargo release date:

23 January 2018

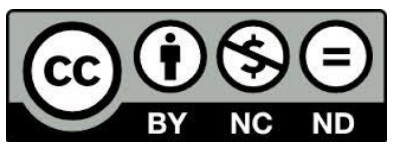

This work is licensed under a

Creative Commons Attribution-NonCommercial-NoDerivatives 4.0 International licence 


\section{(De)composing habit in theatre-as-method}

\section{Ruth Raynor}

\section{ABSTRACT}

Research encounters, like other encounters, differently facilitate the co-constitution of the subject, and incite more or less intense processes of change. But how to understand that change in a context of on-going difference? To explore this question I draw on a series of theatre workshops developed with unemployed and precariously employed UK women who worked together to share experiences of austerity and coproduce a fictional play. A number of women suggested that "something felt different" as a result of or in the moment of theatre participation. Reflecting on this I consider how games and exercises enmeshed and resettled the strange and the familiar; this intensified the volatility of habit and opened new possibilities for connection and relation between women. Therefore in this article I (1) explore recent ontological theorizations of habit in cultural geography to conceive volatile habit in and as multiple processes of (de)composition, and (2) think this through our own theatre activity as well as Boal's approach to "demechanization" to highlight the importance of the method for geographical research. This emphasizes the significance of micro-intensity changes. It expands potentiality of collaborative theatre making beyond the service of instrumental or ideological functions and it blurs binaries between activity and passivity, theatre and everyday life.

\section{Key Words: Theatre, habit, embodiment, non-representational theory, participation}

\section{INTRODUCTION}

This article explores recent ontological theorizations of habit in cultural geography (see Bissell, 2011; Bissell, 2014; Dewsbury, 2011) to develop novel understandings of the experience and potentials of encounters with participatory theatre practices. Therefore it builds from existing work in geography on embodiment, affect, and performance (McCormack, 2008; McCormack, 2013; Thrift, and Dewsbury, 2000) and a developing field of work across theatre-geography (Rogers, 2010; Pratt and Johnston, 2013; Johnston, and Bajrange, 2014.) Empirically, the article draws on theatre exercises undertaken with a group of unemployed and precariously employed women in the 
United Kingdom from the outset of "austerity." Women enacted and reflected on everyday experiences and developed fictional characters through theatre techniques and exercises. Using these methods we explored encounters that co-constituted (and exceeded) austerity for women embedded in a region significantly affected by deindustrialization (on these impacts, see Hudson, 2005; Hudson, 2013. This process of collaborative theatre making supported the cogeneration of a fictional script (see Raynor, 2016, for more on this process) that, in performance, could open new possibilities of connection and relation with audiences, and new possibilities of connection and relation between women were opened by theatrical encounters in the development workshops. In this article I focus on the latter process, which I explore as a form of experimentation with the volatility of habit (see Bissel, 2015, on the various "intensities of habit") that facilitated novel embodied and emotional experiences. To frame this discussion I think theories of volatile habit (through Dewsbury and Bissell 2015 and Grosz, 2013) in relation to Boal's (2002, 2008) approach to “demechanization." This is to emphasize both the novel experiences facilitated by theatre encounters and the significance of small or micropolitical changes that could emerge from such encounters.

I draw attention then, to multiple processes of (de)composition (Deleuze, 1998) at the intersection of habit and change and consider what concepts of volatile habit might offer to theories and practices of collaborative theatre making. Research encounters, like all encounters, differently facilitate the coconstitution of the body subject and therefore incite more or less intense processes of change amidst ongoing difference (see Dewsbury, 2011, for more on the encounter, habit, and change, and Wilson, 2016, on geographies of the encounter). I draw on theories of habit to engage with "little" (Balfour, 2009) or micropolitical change in relation to our theatre-making process. I argue that the change collaborators described or otherwise expressed took place in a context of (more or less intense) ongoing difference, was intangible, was refracted in and through other processes, and yet coconstituted the becoming body subject. Here then, I draw on theories of habit to attempt to understand the elusive and subtle change that women described and that I felt, in relation to our theatre work. I draw on theories of 
habit to think about change because habit is a mechanism whereby things endure but also a site and source of change. ${ }^{1}$

The habit that I engage here is dynamic, lively, and future oriented (after Grosz, 2013.) Therefore, to understand how change is enacted in and through habit, I suggest that it constitutes flows of composition and decomposition where lines between what composition and decomposition are become blurred. Here (de)composition is taken from Deleuze(1988) on Spinozan ethics. This refers to the composition or decomposition of bodies (or parts of bodies) as an always relational process: "When a body encounters another body, or an idea another idea, it happens that the two relations sometimes combine to form a more powerful whole, and sometimes one decomposes the other, destroying the cohesion in its parts" (Deleuze, 1988: 19). Therefore if habit is a form of encounter between the parts that coconstitute body subjects, then how are those parts (de)composed in the process? More specifically here, if habit constitutes difference and in doing so constitutes multiple processes of (de)composition, how did our theatre techniques become enrolled in those processes of change? I consider these questions through some of the exercises that we used and through their repeated practice as, over time, they enmeshed and resettled the strange and the familiar.

\section{ZIP ZAP BOING}

I begin in a dusty blue room. Thirteen women; children's pictures on the wall; faded toys; a tea urn. Us all milling around. A firm sense that this means far more to me than it does to anybody else. A deep breath, chairs shuffled out of the way, last gulps of tea, sun streaming through the window. We take off our shoes. An introduction to the project and:

Gabbie: Let's start by telling us your name and something interesting about yourselves.

Laura: I've got bipolar.

\footnotetext{
${ }^{1}$ I want to draw attention again here to Dewsbury's (2011) essay, "The Deleuzian-Guttarian Assemblage: Plastic Habits," and particularly his engagement with Malabou's (2008) work on plasticity. This provides a framing beyond the scope of this article for understanding both the complexity of encounters between bodies and parts of bodies, and the plasticity of habit, that is neither always on the move nor fixed, rigid, and repeated. As I do so, I consider relations between theatre practice and change in a context of ongoing difference; that is where habit is already thought to be more or less volatile.
} 
Robyn: I'm a granny with three motorbikes.

Bella: I've been on page three of the Sun, but not as a model.

Liz: I’ve got seven kids.

Claire: I’ve got five kids.

Roz: I've lost ten stone.

Jane: I've just found a lump.

We found out later that it was benign, but in that moment Jane describes her loneliness; she doesn't have anybody else to talk to about what is going on and we listen and respond, just as we do to each of the expressions. I am surprised that people are so open so early on and I feel a buzz of reciprocal investment: active contagious participation, connections across, interest, words of praise and sympathy, reassurance bouncing back and forth. I sense a shift in the intimacy of our relationships.

Next we play "Geordie zip-zap boing." Here you pass a word and an action around and across the circle, quick fire, usually zip, zap, or boing, but this time in a North-East dialect: "Alreet," "Alreet," "Alreet," "Canny," "Giz a tab.” It's fast and you have to pay attention. Self-conscious at first, words are mumbled monotone, or sarcastically, lots of laughing — a block, a barrier; distance. But then, focus, speed, concentration takes over: “Alreet," "Alreet," “Alreet," (faster), "Canny," "Arggh. Did it wrong," “Canny," "Alreet," "Alreet," "Giz a tab.” It moves and flows through the circle. We've got it as silliness is folded into seriousness and back again, as a will to complete the activity seems to overpower the embarrassment. "Excellent." Next, “The Sun Shines On ....” We sit on chairs in a circle. I give some instructions and then demonstrate the game by standing in the middle and exclaiming, "The sun shines on ... anybody with brown hair." Immediate motion as women with brown hair get up and move to another chair; a clash of bodies, me almost sitting down on top of you, a jokey shove. As I take a seat, Claire is left standing ready to take her turn. The game starts safely:

Claire: 
The sun shines on ... people with white shoes on.

Hannah:

The sun shines on anyone who has got ... blue eyes.

Liz:

[Pause]

Gabbie:

Don't worry about the silence, an idea will come.

Together we expand the boundaries for the game. One woman takes a risk, and then another:

Jane:

Everybody who believes in God.

Bella:

Who had sex in the last week?

Claire:

Who's wearing black knickers?

I feel myself opening toward this, enjoying the strangeness of sharing secrets with people I don't know, and the speed with which it made them feel closer. I look around and several women are sitting forward, alert, waiting for a reason to get up-eyes focused on a spare chair, keen to avoid being left behind. Others linger on purpose to get a chance to speak. The exercise itself becomes a shared experience as well as an opportunity to explore our differences and things held in common. We transit again to one in a series of exercises that has us moving together around the space-sensing each other, feeling when to stop, when to speed up, when to slow down together without need for verbal communication. This form of interaction felt joyful. It helped me to attune to those around me while feeling both autonomous (singular) and connected to, intimate with, other women in the space. 
Engagement was generally tentative when we introduced a new game, especially at the start of a session, but things soon warmed up and opened out. Slowly over time, week after week, the games became less strange, less likely to be imbued with anxiety or excitement; the games became more like friends. Some were more popular than others. Shuffle Monster was a particular favorite. This began with call and response, then a silly version of "catch" with chairs, a strange walk, and a dodgy French accent. One woman (the shuffle monster) exclaimed, "I am the shuffle monster and what do I do?” We all replied, "You shuffle!" The games traveled out of this space as they were shared with children and neighbors. We enjoyed them, because, as Bella put it:

It's like being a kid again, you build confidence because you do something and you think that it will be embarrassing but everybody is doing the same so that becomes different.

And as she later said in an interview:

It's like what are we bloody doing here we're grown adults, but why not, why not run around and have a laugh ... do you know what I mean? Why not do something just because it feels good?

Bella wasn't the only person to suggest that through this process something shifted. As Sarah said in an interview later on:

When you came in on that first day, you know when the sports woman was there, and you said theatre a lot of people were pulling a face, and I thought I wouldn't come, because people didn't seem interested and I was saying I hope it goes off okay ... I might not come, because I don't want it being all negative. ... The games seemed to loosen everyone up though ... We just had a laugh. If anybody is self-conscious about themselves then that first game outside, with the builders on the roof and that, then that broke the seal.

\section{For Robyn:}

It has brought out ideas in people, and brought out things that we didn't know we had ... it brought out what people didn't realize they could do, a bit of achievement, personal experience, by the time you've done it is done.

As Bella finally went on to say: 
Often everything we do is a front, em ... so it was quite nice to be stripped bare of that, that was quite nice.

In this process I was interested in the felt sense that something was different amidst or as a result of participation in these theatre activities. Without wishing to overstate the effects of the process, the sense of feeling or becoming "like a kid again," being "stripped bare," or "breaking the seal" is significant. What might that mean, or do, or even undo, in this empirical process? Is it that responsibility diminishes, that possibilities open up, that we connect through play and a common goal, that (as Bella put it) we test things out in a safe environment? Does this become a momentary unravelling of the habits that age us? How does this (however temporarily) open certain frames of possibility for interaction? How to think about the implications of this, for the kind of research material that we developed together?

Many performance theorists and practitioners have reflected on, galvanized, and attempted to understand relations between applied theatre (Kershaw and Nicholson, 2011) and change (for reviews, see Nicholson, 2005; Balfour, 2009). In practice, theatre as a method for research and for social transformation could be imagined across several registers. For example, Key Change (2015) developed with women in UK prisons by the Open Clasp theatre company was initially commissioned to facilitate encounters between male prisoners and stories told by women prisoners, but the project also aimed to challenge what was deemed by the company to be a harmful punitive system, and to support the company's broader aim of tackling widespread injustices associated with patriarchy. The company's aim to "change the world one play at a time" (McHugh, 2016) feeds into a difference that Schechner (1985) delineated between the concepts of transportation and transformation. Transportation implies a temporary change occurring as spectators, participants, or performers are "taken somewhere" through performance. Transformation infers some kind of permanent shift, which might emerge after the escalation of several transportations but cannot be an assumed consequence of witness or participation. Relatedly, Johnston and Bajrange (2014) suggested that theatre's ability to evoke emotional transportation and create a "bridge of empathy" can affect how audiences and participants engage with broader social and political frameworks. Jackson (2011) and Kershaw (1992) emphasized theatre as a shared experience that is able to interrupt processes of individualization or fragmentation. By bringing transportation and transformation into relation, Schechner evoked potential connections 
between small (or micro) political changes and bigger (or macro) political changes (effects or impacts) that might take place as a result of theatre practice and participation. Some claims about the impacts of theatre practice might be problematic, however. For example, Balfour (2009) developed from Chamberlain (Kramer et al. 2006) who suggested that relations between social change and applied theatre can be fraught when this 'begins to suggest that what's 'applied' in applied theatre is not 'theatre' but a specific set of ideological values" (93). In this context, Balfour raised the question of the scale and type of change that we might expect to occur amidst theatre participation or witness. He suggested that a relation between applied theatre and the intention of "big" change might become increasingly necessary for the marketization of applied theatre as funding becomes harder to obtain. This demand for change becomes unproductive or even harmful, however, where it reduces applied theatre practice to a specific instrumental function, including the assertion of particular ideologies or the demand for some kind of measurable change or improvement in participants. Instead he suggested that a theatre of little changes could muddy a recurring polarization in applied theatre between aesthetics and instrumentalism (also see Thompson, 2009) and allow for moments of unplanned, improvised change. Small changes might not be predetermined but could surprise, they might not be measured, and they might be intangible. Therefore taking from the spirit of a "theatre of little changes," I think micro intensity changes in the context of our project by engaging with habit as multiple forms of (de)composition. As I do so, I give focus to the mechanisms and techniques of theatre making that might engender change. In doing so I shift the focus away from intentionality so that theatre as a method for research might not facilitate predetermined or ideological outcomes but rather open potentialities for a sensing body subject that connects, expresses, and explores.

\section{EAT A BANANA: FLOWS OF (DE)COMPOSITION}

Often habit is reduced to a repeated, embodied, and unconscious act, an inescapable cognitive loop, or even a prison that renders subjects passive and oppressed; as Grosz (2013) put it, "after Sartre, Kant and Descartes habit becomes a form of mechanism that arrests consciousness, thought and freedom” (217). The ontologies I draw on here, however, avoid fixing or moralizing habit or making its disruption or surfacing stable. Using Grosz (2013) Grosz on Ravaisson, Bergson, and Deleuze, I address concepts of habit that link it to an "ever moving world." Habits therefore become thought of as 
modes of encounter, materiality, and life, rather than restrictive forms of fixity and repetition. If bodies are always becoming in relation, then habit is not confined to (and need not confine) the body subject, but becomes in relation between body subjects, objects, landscapes, and so on (see Dewsbury 2011, Dewsbury, J. D. 2011; Bissell 2015, Bissell, D; Dewsbury and Bissell 2015). Although habit has not to date been framed explicitly as processes of composition and decomposition, this is implicit in some recent work (see Bissell 2014 on stressed bodies and Berlant 2011, on the slow death). Therefore rather than thinking about habit as a form of mediation that either facilitates good-activity-freedom or bad-passivity-imprisonment (again see Grosz, 2013), I consider ways in which particular habits might (de)compose parts of the body subject and ways in which habits themselves are (de)composed. Before returning to our own participatory theatre practice, I think more about the complex material and immaterial relations that become habit as an always moving process of (de)composition. For Beckett (1948) habit is the ballast that chains a dog to his vomit; habit is also necessary for the continuation of life. Habit is breathing. Because Beckett is exemplary at making habit volatile-by making habits and the environments in which habits play out so explicitly strange-I use "Krapp's Last Tape" to show exactly what I mean by the volatility of habit and by habits as processes of (de)composition.

Have just eaten, I regret to say; three bananas and only with difficulty refrained from a fourth. Fatal things for a man of my condition. (Beckett 2006: 4)

The curtain raises on “a Late Evening in the Future.” It's Krapp’s sixty-ninth birthday. He listens to a tape of himself speaking on his thirty-ninth birthday and dislikes the man he barely recognizes. Making recordings and playing them back is one of Krapp's many habits. Eating bananas is another. This compulsive consumption is almost definitely the source of his "bowel problems" and yet he doesn't stop. And what about the poor actor playing Krapp? What about his bowels? So, Beckett's joke is double, as he gestures toward "life (as) habit, or rather life (as) a succession of habits, since the individual is a succession of individuals." In this play he experiments with the materiality of performance through a folding of form and content, actor and character. Just as the character Krapp is caught in a loop of activity_listening to recordings of himself, making recordings of himself, and eating bananas—so the actor playing Krapp is caught in the same loop of activity, not just in a single performance but often, night after night 
after night. Objects—-the tape recorder and the banana-become active; they sustain the habit, they become a part of the habit.

Krapp (and perhaps the actor performing Krapp) becomes constipated, not from eating one banana, but from repeatedly eating bananas. The composition of this habit, sustained in part by seemingly endless availability of bananas, slowly decomposes the body as it disrupts Krapp's bowel functions. This hidden infrastructure is drawn to the surface only at the point of discomfort. And if, as we are led to suspect, Krapp's increasing irritability might be bound in part to his physical condition, then irritability escalates as a relation with compacted bowels - as a relation with the repeated consumption of bananas. Therefore the habit has material and affective consequences for Krapp. Because repetition is difference, habit becomes dynamic: constituting shifts that (de)compose the body's capacity to act or be acted on, and to affect and be affected in a range of different ways (Dewsbury and Bissell 2015).

Flows of (de)composition including flows of activity and passivity become manifest multiply across a range of forces that constitute Krapp's habits. For example, Krapp (the actor playing Krapp) might on occasion register that again he eats a banana, but not how his bowels extract sugar from the banana and become shaped by this repeated act. The comfort that the bananas' ongoing presence brings might be sustaining if the loss of the banana would lead to a loss of hope about anything. This comfort could coexist alongside pain or discomfort in the bowels. So habit as process of (de)composition might be manifest multiply across material and immaterial forces. In this way the subversion of a habit might not be thought of as a solely willful act. It might be incited by the shock of physical pain, for example, as the relation between banana and bowel finally reaches a certain threshold and in doing so inflicts pain on the body (see Bissell 2014). Slippage might take the shape of a new act that might in part emerge as a result of a change in environment; for example, a new affinity for apples occurring alongside the sudden proliferation of apples. The act of eating apples becomes bound with what came before, however; it must at least at first be folded into how that body has become in and as relation with bananas. Therefore the forces of the habits do not have a bounded start and an end (again see Dewsbury 2011).

For Bissell (2011) habit is not always un-thought, sensed, or instinctive. Various relations with a particular habit might ebb and flow so that habit might be differently consciously engaged. For example, at times Krapp reflects on the damage he is doing to his body 
when he eats a banana, even on occasion "resisting from a fourth." Krapp shows us the volatility of habit: Habit becomes the folding of passive and active bodily affections that compose everyday encounters (Dewsbury and Bissell 2015) and through the multiple forces entangled in habit, different forms of passivity and activity rub together. In this context theatre processes cannot be considered as surfacing fixed thinking and embodied habits or subverting stable repeated practices; instead they take place in and coconstitute an always-changing world. Like other forms of change, they must be enrolled in existing habitual process or act a shock from the outside that can be debilitating as well as liberating (Bissell 2014).

Beckett in his way constitutes what has been generally understood as a dismal account of habit as "the ballast that chains a dog to his vomit." Grosz (2013) showed a different emphasis in relation to what habit is or does. A habituated body can know without knowing, that is sense or otherwise become without cognition. "Habit is the accommodation of life to its most insistent and repetitive forces and tasks, life's transformation through its engagement with a world larger than its will or consciousness" (Grosz 2013). In this way, habit does not reduce or limit consciousness but instead becomes an opening toward different forms of consciousness. Habit is activity freed by the dampening of cognition where activity is instinct, desire, and survival. Our relations with a larger world constitute habits, and through those relations space is freed for more than survival.

The alarm summons up a chain of actions: opening our eyes, turning off the alarm, getting out of bed, putting on slippers and beginning the day. It is only because we undertake these activities in a state of half-consciousness that we have the energy and interest to undertake less routinized actions, to elaborate relatively free acts. Habits, incorporating memories of past performances in similar contexts, leave both consciousness and the energetic forces of the body able to address other issues than the habitual only because the habitual accommodates so much of what is required from us ... habit is an anchor, the rock to which the possibilities of personal identity and freedom are tethered, the condition under which learning is possible, the creation of a direction, a “second nature," an identity. (Grosz 2013: 226 on Bergson)

For women encountering a range of cuts and reforms (as those experiences relate to broader work on precarity; see, e.g., Puar et al. 2012) change and disruption demanded energy to sustain acts of simply getting on and getting by. In that context the creativity- 
freeing capacities of habit became dampened by disruptions to infrastructures with which habits had become entangled. In the same way, if the alarm clock and the slippers are withdrawn or swapped one day, what does that do to the habit? She adjusts. What if they are removed or swapped again and again and again? She adjusts and adjusts and adjusts until adjusting becomes ordinary. What energy does it require to wake up? How does this make a banal act feel like something more significant and demand decision making and creativity that can't be used elsewhere? How does this affect relations with or attachments to habit in general as the infrastructures that they are bound with can no longer be relied on? Despite this, if habit can constitute many forms of composition and decomposition, then it is also possible to recognize Krapp and Beckett's account of the $\operatorname{dog}$ and his vomit. Too much of a certain kind of structure can also become exhausting at times, differently than too much change or disruption. For example, women explained how repetitive tasks in some jobs had become harmful. They might not require much cognition and leave plenty of space for creativity, but if one is routed to a task then the field of possibilities for expending that creative energy is closed down; this can wear down the body, too. Relatedly, Bissell (2014) Geoforum51:191-201. showed how commuting bodies become stressed and reach a tipping point of debilitation and Berlant (2011) on the "slow death" showed slow forms of decomposition taking place through habituated forms of relation between body subjects, work, and consumption. This is a consequence of the broad-scale supply of unhealthy food and unstable, poorly paid work. Different habits then constitute different forms of (de)composition, feel good or bad sometimes simultaneously, and become in relation to particular infrastructures, labor practices, and so on.

To think more about the implications of this for understanding the ambiguous change that collaborators described in relation to our collaborative theatre project, I return attention to the games and exercises that we used. At first, unfamiliar theatre activities might have facilitated a shock from the outside as they disrupted collaborators' practiced modes of relation, but over time they became familiar, settled. Like the eating of apples after the eating of bananas, theatre practice became folded into other forces from outside of that practice. Therefore such practices became enrolled in a general flow of the (de)composition of habit and subsequently the (de)composition of material and immaterial forces coconstitutive of bodies.

\section{ROUTINE AND VOLATILITY IN THEATRE PRACTICE}


In this section then, I want to think different potentialities of habit through our theatre games, which produced a volatility of habit and then became routine as they were practiced at the start and end of every session. Thinking and doing habit in this way complicates binaries that can surface between active and passive participation. For example, in applied theatre and particularly "theatre in the community," emphasis is placed on "activity and involvement rather than passivity and uncritical consumerism" (Nicholson 2005). This involves the expectation or desire that audiences, participants, or both become "more actively" engaged with a particular topic or process as a consequence of participation. As Grosz (2013) suggested, however, it is possible to be active in ways other than the cognitive, so this expands opportunity for thinking activity and passivity multiply across a range of material and affective relations.

Boal's (2008) theatre techniques are aimed at the production of the spectactor so that audiences or participants could become dynamically involved in the development of theatre. For Boal, enhanced levels of activity in the theatrical space are something to be desired and become a "rehearsal for reality." This means that certain forms of social change might be rehearsed through theatre and then enacted in everyday life. Thinking about habit as multiple flows of (de)composition including multiple flows of activity and passivity might shift how I understand the problem of change in our own participatory theatre research process, not least since different (de)compositions of activity and passivity can coexist multiply. Further passivity and activity might simultaneously decompose and compose parts of the body and as in Beckett's work with the actor and the character, theatre and everyday life might not be thought of as separate but instead (and this is not quite counter to Boal's account) connected through the moving, performing body. In this way one form of activity (cognitive thought) becomes no more privileged than another way of sensing or relating.

For Boal (2002) Boal, theatre games and exercises can open participants up to new modes of relation. Games for actors and nonactors are clustered around practices like listening to what we hear, dynamising several senses, feeling what we touch (restructuring muscular relations), reconnecting memory emotion and imagination. Through processes of demechanization, the exercises attempt to shift habituated forms of relation within and between body subjects and in doing so provide conditions for the incitement of social change. I think this through the notion that habit does not necessarily produce mechanization from which subjects need freeing, but also in a context whereby certain 
habits and infrastructures decompose some body subjects more than others, as we see, for example, in the work of Berlant (2011) on the slow death. How habits are retuned might facilitate different ways of sensing the world and make different ways of becoming in the world seem possible. Theatre games and exercises provide just one among many ways of experimenting with those processes, by, for example, enhancing some sensory capabilities by limiting others.

Drawing on Friere (1970) Boal developed a theatrical system so that audiences could become more active not just in the development of theatre. As he put it:

Hamlet says in his famous speech to the actors that theatre is a mirror in which may be seen the true image of nature, of reality. I wanted to penetrate the mirror to transform the image I saw in it and to bring that transformed image back to reality: to realise the image of my desire (Boal, 2005.)

Thinking about habit as (de)composition, however, might trouble the clear distinction that reoccurs in Boal's work between activity and passivity, composition and decomposition, and provide a different framework for understanding the change potentially effected by participation in particular theatre exercises. Drawing on theories of habit as ontological force, I might consider that the image, the mirror, and the reality Boal described are not separate entities but instead become folded into one another. This means the exercises advocated by Boal among others and used in our project are significant where they facilitate a meeting of the strange and the familiar that intensifies the volatility of particular habits. Theatre technique cannot be disentangled from other habits already shaping and moving bodies in multiple ways. Nevertheless, in the moment of participation, forms of relation might shift as they meet theatre techniquesregardless of how or whether those shifts are registered. According to this framework, the exercises cannot be thought of as surfacing or subverting stable, always unthought habits — creating a temporary or permanent change_-but instead they become bound up in already ongoing difference as they produce different kinds of encounter between bodies and subjects.

\section{$1,2,3$}


To give an example of how this process played out I expand on our use of one of Boal's games: two people stand, face-to-face, eyes locked, and they count to three, taking it in turns number by number.

Person A:

One.

Person B:

Two.

Person A:

Three.

Person B:

One.

Person A:

Two.

Person B:

Three. ... and so on.

This practices a deeply habituated act: counting using language: "One, two, three."

Already the usual rhythms of the activity are disrupted, as we are forced in complicity with a partner. This demands eye contact and an unspoken connection enables the words to flow as two people count together. In this activity collaborators are asked to slowly replace each number with an invented action and sound; for example:

A:

[the cluck of a chicken and the bend of the elbows].

B:

Two. 
A:

Three.

B:

[the cluck of a chicken and the bend of the elbows]. $</$ DIA $>$

And so we enter in to each other's imagined worlds, repeating one another's invented actions and words until the game might become:

A:

The cluck of a chicken and the bend of the elbows.

B:

A whistle and a bend of the knees.

A:

A raspberry and a wiggle of the fingers.

B:

The cluck of a chicken and the bend of the elbows ...

And we repeat over and over again, before restarting the process - trying out different sounds and different images. In this exercise there is a connection between us as we take on the partner's actions and expressions as our own. So if, as Boal would suggest, language or in this case the act of counting reproduces hierarchal forms of convention, then games and exercises might enable participants to replace those forms of convention with their own imagined vocabularies. Boal would argue that moving outside of the box of "1, 2, 3" becomes a kind of liberation, as it offers the participant an opportunity to change the expression. Through repetition, this practice of subversion becomes more finely tuned; that is, the bodily mechanisms that the exercises demand become practiced. If I think again of the habits associated with eating bananas as they become folded into the eating of apples, however, then it is also worth considering that the activities replacing the counting have themselves come from somewhere. The act of blowing a 
raspberry has its own history - that in this situation becomes enmeshed with the act of counting 1.

This game facilitates complex flows of passivity and activity. Collaborators are made passive by the rules of the games. To comply they have to count from one to three with a partner; they have to make eye contact with each other to achieve this aim. Then, later, they have to replace a number with a sound and movement. Some collaborators found this difficult at first. To be "silly" in this way was a scary thing to do. Simultaneously, though, the rules of the game limited choice-either (1) join in, or (2) sit out—and simultaneously opened a field of possibilities (counting can become something other than 1,2,3). A kind of disciplining therefore is integral to this game. Such disciplining, however, produced the conditions for activity where collaborators could speak, move, and connect to one another in unfamiliar ways. In this case structure enabled a certain kind of experimentation.

Two does not have to follow one: An itchy head could do instead. Repeating those actions meant that something impulsive, self-conscious, spontaneous, unthought was given a different kind of attention-was attuned to, reperformed, repeated. You and your partner decided and reproduced the action or sound in that moment of interaction. As a consequence flows of (de)composition associated with the normal act of counting 1 , 2, 3 became volatile. The demand of spontaneity in the invention of a new sound or movement might, for some, act as a (minor) shock and then through repeated practice might improve the bodies' capacity for spontaneity, listening, and attuning. The movements that the exercise demanded might stretch the body, but in such a way that is directed by a partner. Because too much planning rocks the rhythm of this game, perhaps on occasion the present expanded here as futures contracted. As we concentrated I felt the flow of connection between us. This involved a feeling through of the other's limits. It required and therefore practiced trust or exposed the breach of that trust if those limits were tested. In this game I had to believe that my partner would not laugh at me and that he or she would not chose a word or symbol that I could not reproduce. I had to trust. This became a practice in collaboration. The solitary act of counting 1,2,3, became a shared practice of speaking, moving, and making sounds or images together. This exercise simultaneously (de)composed the hegemony of verbal communication, and the act of counting 1, 2, 3, as a solitary process. It created a practice 
in listening and attuning. Over time, through repetition, the familiar act of counting became estranged and the strange act of making sounds and movements became familiar.

If habits are relations between body subjects and their outsides then in this case theatre games made those relations volatile in particular ways, but they did it through using structure and routine. Perhaps therefore structure, techniques, and boundaries made experimentation and trust feel safe or possible. "Habits, incorporating memories of past performances in similar contexts, leave both consciousness and the energetic forces of the body able to address other issues than the habitual only because the habitual accommodates so much of what is required from us" (Grosz 2013: 217-39 on Bergson). The rules and repetition used in this game achieved the same effect. We knew what we had to do and this freed space within those limitations for experimentation. The space that was bounded by the repeated use of these games at the start and end of every session opened a field of possibility for interacting in unexpected ways. As they became familiar and as they were shared, a kind of intimacy emerged between us.

\section{CONCLUSION}

The sun shines on ... anyone who was caught out in that rain on Tuesday.

-Bella

A few of us get up and later this becomes a topic of conversation, as we all had something to say about the rain. Like this process of theatre making, the floods were a meeting of the ordinary and the out of the ordinary and they had enveloped us all in one way or another. Through their repetition, particularly at the start and the end of a session, games and exercises like 1, 2, 3, The Sun Shines On, and Geordie Zip Zap Boing, produced tension between the intensified volatility of habit and forms of (never quite) repetition. A game that pushed bodies to connect, move, and interact in strange ways became familiar, and this made familiar modes of interaction strange. Boal (2002) compared this process to when a person leaves his or her "habitual environment" and visits an unknown country: "Everything seems wonderful, unexpected, fantastic" (or perhaps a little scary or daunting), "but after a few days once again the senses learn to select and the routine starts anew" (30). On visiting an unknown country, the strange but perhaps also the familiar becomes drawn into sharp relief. In the same way, these exercises enabled us to bring ordinary, everyday interactions into a space made strange by 
theatre exercises. This gave us an opportunity to attune to those interactions differently together. For example, by enacting getting out of bed in the morning, what usually happens alone, in a half-asleep zone is performed with others in a dusty blue hall. How does this shift our relation with that habit? In the space made by theatre games, we could play around with the act, change it, and explore it. Different flows of activity and passivity can be facilitated by this experimentation. Just as Krapp and the actor playing Krapp become enmeshed through the materiality of the performance, so the spaces of theatre and everyday life might not be thought of as distinct. Indeed, perhaps there was something about making that "journey to another country" together that strengthened and shifted bonds between us, perhaps even initiated the promise of new bonds. It gave us a shared set of experiences that we could laugh about, feel, and reflect on in the future. This made a difference to the kind of conversations that we had in the process and during interviews at the end: They were conversations between friends, or at least between people who had been through something together. Thinking about the experience and potentials of collaborative theatre making as a method for research in human geography, then, enables us to understand that these encounters can become something other than the service of instrumentality, or the imposition of ideological functions. Activity and passivity are not binary but can flow and coexist in productive (or unproductive) ways through these (and other) approaches. Theatre games and exercises can become an opening up of possibility for collaborative experimentation. Bearing this in mind, more work should be done to consider how, as a method for research, these techniques might allow us to notice, feel, or otherwise register everyday encounters in novel and productive ways.

\section{REFERENCES}

Balfour, M. 2009. The politics of intention: Looking for a theatre of little changes. Research in Theatre Education: The Journal of Applied Theatre and Performance 14 (3): 347-59.

Beckett, S. 1948. Proust. New York: Grove/Atlantic Monthly.

Beckett, S.. 2006. Krapp's last tape and embers. London: Faber and Faber.

Berlant, L. 2011. Cruel optimism. Durham, NC: Duke University Press.

Bissell, D. 2011. Thinking habits for uncertain subjects: Movement, stillness, susceptibility. Environment and Planning A 43 (11): 2649-65. 
Bissell, D.. 2012. Agitating the powers of habit: Towards a volatile politics of thought. Theory and Event 15 (1).

Bissell, D.. 2014. Encountering stressed bodies: Slow creep transformations and tipping points of commuting mobilities. Geoforum 51:191-201.

Bissell, D.. 2015. Virtual infrastructure of habit: The changing intensities of habit through gracefulness, restlessness and clumsiness. Cultural Geographies 22 (1): 127-46.

Boal, A. 2002. Games for actors and non actors. London and New York: Routledge.

Boal, A.. 2005. Legislative theatre: Using performance to make politics. London and New York: Routledge.

Boal, A.. 2008. The theatre of the oppressed. London: Pluto.

Deleuze, G. 1988. Spinoza: Practical philosophy. London: City Lights.

Dewsbury, J. D. 2011. The Deleuze-Guttarian assemblage: Plastic habits. Area 43 (2): 148-53.,

Dewsbury, J. D., and D. Bissell. 2015. Habit geographies: The perilous zones in the life of the individual. Cultural Geographies 22:21-28.

Friere, P. 1970. The pedagogy of the oppressed, trans., trans. M. Bergman Ramos. New York: Continuum.

Grosz, E. 2013. Habit today: Ravaisson, Bergson, Deleuze and us. Body and Society 19 (23): 217-39.

Hudson, R. 2005. Re-thinking change in old industrial regions: Reflecting on the experiences of North East England. Environment and Planning A 37 (4): 581-96.

Hudson, R.. 2013. Thatcherism and its geographical legacies: The new map of sociospatial inequality in the divided kingdom. The Geographical Journal 179:377-81.

Jackson, S. 2011. Social works. London and New York: Routledge.

Johnston, C., and D. Bajrange. 2014. Street theatre as democratic politics in Ahmedabad. Antipode 46 (2): 455-76.

Kershaw, B. 1992. The politics of performance: Radical theatre as a political intervention. London and New York: Routledge.

Kershaw, B., and H. Nicholson. 2011. Research methods in theatre and performance. Edinburgh, UK: University of Edinburgh Press.

Kramer, A., Chamberlain, F., McNamara, C., et al. 2006. Applied theatre/drama: An edebate in 2004. Research in Drama Education 11 (1): 90-95.

Malabou, C. 2008. What should we do with our brain? New York: Fordham University Press. 
McCormack, D. 2008. Geographies for moving bodies: Thinking, dancing, spaces. Geography Compass 2 (6): 2822-36.

McCormack, D.. 2013. Refrains for moving bodies. London: Duke University Press.

McHugh, T. 2016. On Open Clasp Theatre Company and "Key

Change." http://www.openclasp.org.uk/our work/detail/Key-Change/83 (last accessed 3 May 2016).

Nicholson, H. 2005. Applied theatre: The gift of theatre. London: Palgrave.

Pratt, G., and C. Johnston. 2013. Staging testimony in Nanay. Geographical Review 103 (2): 288-303.

Puar, J., L. Berlant, J. Butler, B. Cvejic, I. Lorey, and A. Vujanovic. 2012. Precarity talk: A virtual roundtable with Lauren Berlant, Judith Butler, Bojana Cvejić, Isabell Lorey, Jasbir Puar, and Ana Vujanović The Drama Review 56 (4): 163-77.

Raynor, R. 2016. Dramatising austerity: Holding a story together (and why it falls apart ...). Cultural Geographies. Advance online publication. doi:10.1177/1474474016675564

Rogers, A. 2010. Geographies of performing scripted language. Cultural Geographies 17 (1): 53-75.

Schechner, R. 1985. Between theatre and anthropology. Philadelphia: University of Pennsylvania Press.

Thompson, J. 2009. Performance affects: Applied theatre and the end of effect. London: Palgrave Macmillan.

Thrift, N., and J. D. Dewsbury. 2000. Dead geographies and how to make them live. Environment and Planning D 18:411-32.

Wilson, H. 2016. On geography and encounter: Bodies, borders and difference. Progress in Human Geography. Advance online publication. doi:10.1177/0309132516645958 